This item was submitted to Loughborough's Research Repository by the author.

Items in Figshare are protected by copyright, with all rights reserved, unless otherwise indicated.

\title{
Deformation property measurement for single anisotropic conductive adhesive particles
}

PLEASE CITE THE PUBLISHED VERSION

PUBLISHER

(c) IEEE

VERSION

VoR (Version of Record)

LICENCE

CC BY-NC-ND 4.0

\section{REPOSITORY RECORD}

Dou, Guangbin, David C. Whalley, and Changqing Liu. 2019. "Deformation Property Measurement for Single Anisotropic Conductive Adhesive Particles". figshare. https://hdl.handle.net/2134/4198. 
This item was submitted to Loughborough's Institutional Repository (https://dspace.lboro.ac.uk/) by the author and is made available under the following Creative Commons Licence conditions.

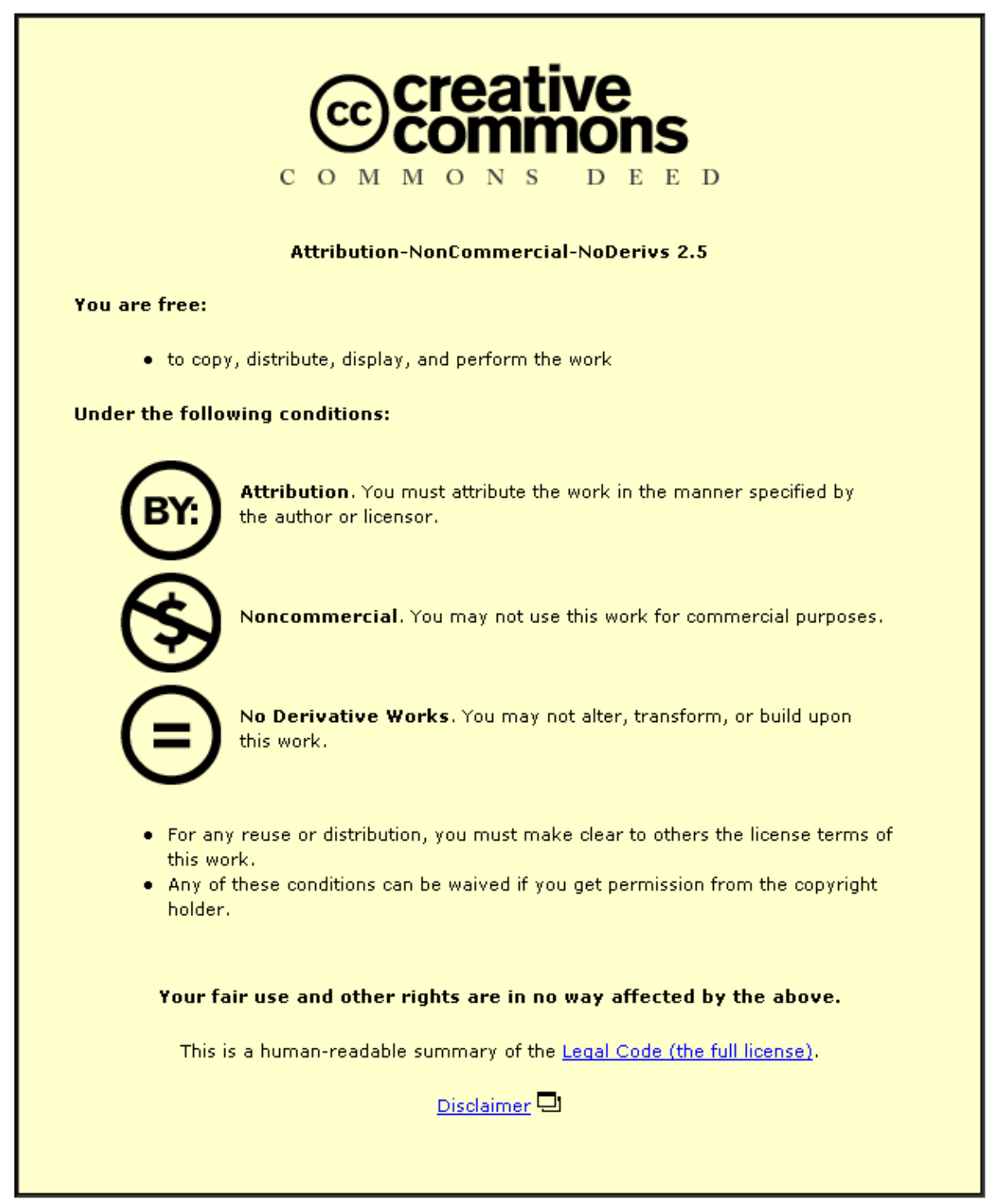

For the full text of this licence, please go to: http://creativecommons.org/licenses/by-nc-nd/2.5/ 


\title{
Deformation Property Measurement for Single Anisotropic Conductive Adhesive Particles
}

\author{
Guangbin Dou, David Whalley and Changqing Liu \\ Loughborough University \\ Wolfson School of Deformation and Manufacturing Engineering, Loughborough University, Loughborough, \\ Leicestershire, United Kingdom, LE11 3TU. \\ Email: gb.dou@lboro.ac.uk; D.C.Whalley@lboro.ac.uk; c.liu@lboro.ac.uk. Phone: +44(0)1509227677.
}

\begin{abstract}
Anisotropic Conductive Adhesives (ACAs) consist of a polymer adhesive matrix containing fine conductive particles. The primary objective of this experimental research was to establish a clearer understanding of the effects of the bonding force and load rate on the deformation of individual ACA particles. This has been achieved through measurements of the deformation against force using a specially configured Nano-indenter machine, where the "indenters", instead of being a point, had a flat tip $30 \mu \mathrm{m}$ in diameter. The merit of using this machine is that very small forces, of the order of $100 \mathrm{mN}$, can be accurately applied to the particles to a resolution of $100 \mathrm{nN}$ and the resulting deformations, of less than $6 \mu \mathrm{m}$, can then be recorded to a resolution of $0.1 \mathrm{~nm}$. The results showed that the ACA particle deformation was not linear and the force/deformation at which particle crushing occurs could be determined from the profile of the force versus deformation. The crush points and the deformation processes were affected by the load rate.
\end{abstract}

\section{Introduction}

ACAs are conceptually a simple method for achieving high density interconnection of electronic components. They offer other potential advantages in terms of low assembly temperature, being lead free, reduced package size, and compatibility with metallizations unsuitable for use with soldering processes $[1,2]$. Whilst unlikely to become a mainstream alternative to soldering for PCB assembly they are well suited to a number of niche applications, such as hybrid circuit assembly, chip on board/flex and LCD assembly. ACAs are therefore experiencing a significant growth in use, although some aspects of their performance, particularly in terms of yield and reliability, are not yet fully understood. The electronics industry is therefore very interested in the joint reliability of ACA based assemblies. The deformation properties of the conductor particles are very important and understanding their behaviour will help to improve the packaging process and to reveal the mechanisms that cause reliability problems.

ACAs are designed to achieve fine pitch electronics assembly, providing electrical paths as well as mechanical connections between the conductive pads on electronic components and substrates. There are two forms of ACA: films, which are often referred to as ACFs; and pastes, refereed to as ACPs. There are also two types of adhesive resins used, thermosetting and thermoplastic, and three kinds of particles: rigid or solid metal particles; compliant or polymer cored particles; and solder particles [3]. The particles used in this experiment were compliant particles. Figure 1 shows all these options.

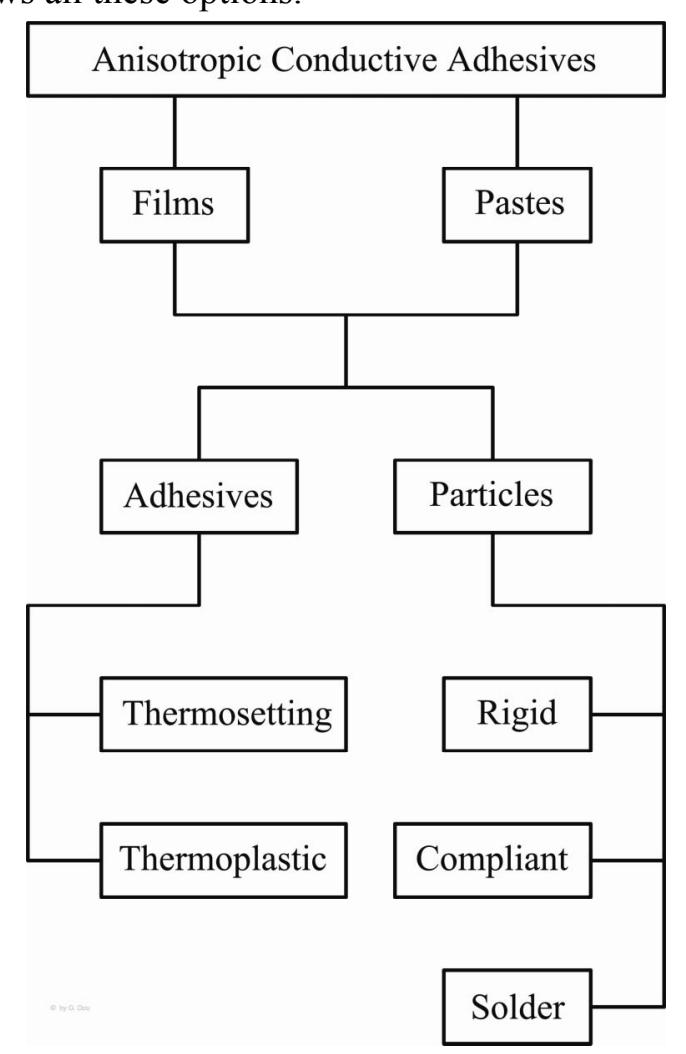

Fig. 1. ACA types and their typical compositions[3]

ACA particles are generally dispersed randomly in the polymer at a low density, however, ACAs have been developed where the particles are uniformly separated in the same non-conductive 
plane [4]. These two types of materials are referred to as random ACAs, and ordered ACAs respectively.

It is difficult to measure deformation of a single ACA particle due to the small particle size and the roughness of the contact area. When considering the function of the particles, two kinds of deformation properties can be identified, i.e. micro properties and macro properties. Micro properties relate to the hardness of the materials constituting the ACA particles, i.e. the particle micro mechanical properties, whilst the macro properties relate to the whole particle deformation properties.

The hardness of the ACA particles is critical to the ACA material performance, because it determines how the particle deforms and the resulting contact forces with it. Previous research using a nano-indenter on cross sections of ACA samples assembled at different pressures showed that ACA particle deformation resulted in a reduction in hardness of the polymer core with increasing particle deformation. It also showed that the particle hardness after assembly varied within the particle, due to the non-uniform plastic strain within the particles [5].

Little research has been conducted into the macro properties of ACA particle deformation, especially for a single particle. The reason for this is that the particles are too small to be deformed in normal material testing machines and are also very fragile. However, the deformation properties have been modelled, for example, using an equivalent spring method to simplify the complex deformation situation [6]. This methodology could significantly reduce the analysis computer CPU time compared with FE modelling and makes ACA process modelling possible.

Previous work has however determined the average mechanical deformation properties of a large number of ACA particles [7-8]. The difference between these previous studies and the research presented here will be discussed later.

Polymer cored, Ni/Au coated ACA particles have been shown to have visco-elastic properties due to the properties of the polymer core [1]. The deformation therefore depends on the load rate. This paper will report an investigation of the properties of individual particles and how the load rate affects the loading process and the resulting deformation.

\section{Materials and Methods \\ Materials}

Commercial ACA particles, $5.75 \mu \mathrm{m}$ in diameter, were used in this research, which were micro spheres of a cross-linked co-polymer resin of divinyl-benzene coated with $\mathrm{Au} / \mathrm{Ni}$ layers as shown in Figure 2.

These particles are specifically designed for use in ACA/ACF applications and have a $N i$ layer about $50 \mathrm{~nm}$ thick and a $A u$ layer, less than $30 \mathrm{~nm}$. The metal coating layers on the ACA particles are not homogenous as shown in Figure 3.

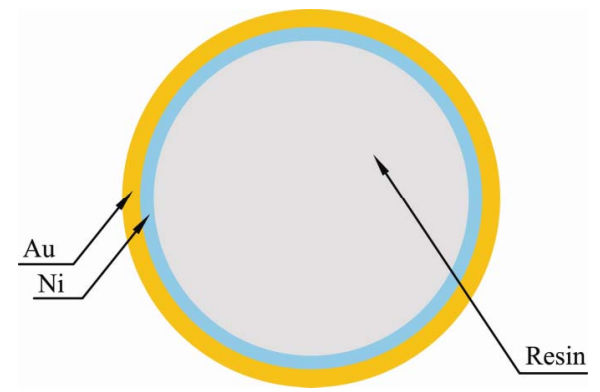

Fig. 2. ACA particle configuration

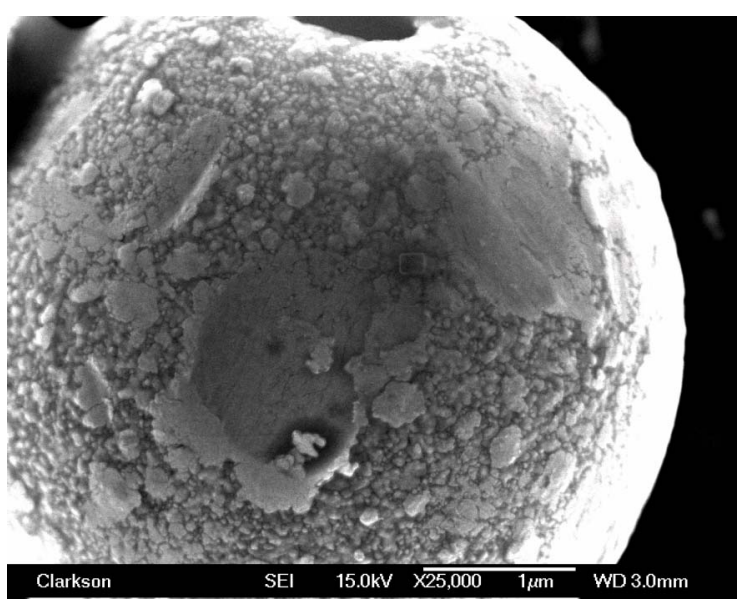

Fig. 3. SEM of a particle

\section{Methods}

\section{Experiment Setup}

This experimental research was accomplished using a NanoTest ${ }^{\mathrm{TM}}$ Machine, which is normally used to measure micro materials properties, such as in Nanoindentation Testing, Nano-Scratch Testing and Nanotribometry [9]. However, this machine has been adapted to deform fine particles using a flat tipped punch. The NanoTest pendulum and sample stage are schematically shown in Figure 4, where a flat tipped punch instead of the diamond indenter was used in this experiment. The load resolution of this machine is $100 \mathrm{nN}$, and displacement resolution $0.1 \mathrm{~nm}$. 


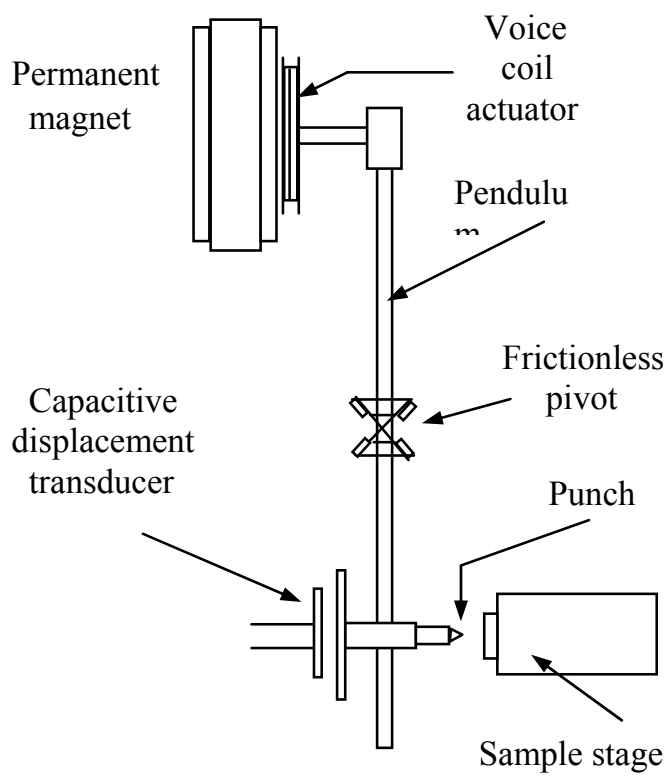

Fig. 4 Schematic diagram of the nanoindentor

The deformation process is schematically shown in Figure 5, where the microscope slide is fixed and the punch moves from left to right to deform the particle.

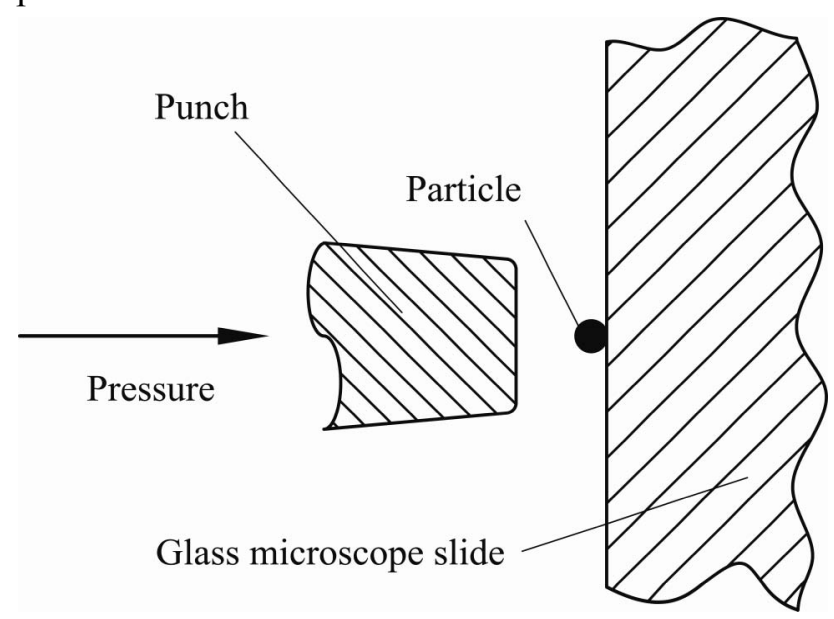

Fig. 5 The particle deformation process

The punch must be aligned before it can deform the particles accurately, because each different punch has a different size, and also the same punch can not be re-fixed into the same position on the machine in different experiments.

The tests involved force controlled deformation of the particles, where the force was increased linearly with time and the resulting deformation monitored. The load force and the deformation were recorded by the nano tester, and then saved in a file in the control computer.

\section{Punch and Base Stage}

In these experiments, the particles are deformed between two parts, one is the load part, and the other is the base part that holds the particles steady. They are referred to as the punch and the base stage respectively in this experiment. In order to obtain an accurate measurement of the deformation of the polymer cored particles, the punch and the base stage must be much harder than the particles, so that the particles do not indent into them. Therefore, HSS (high speed steel) and a titanium alloy were evaluated for making the punches, as shown in Figure 6, where Figure 6 (a) and (b) are HSS punch heads and (c) and (d) were Ti punches. Considering the particle size and the required planarity of the punch head surface and the base surface, and also the Nano-indenter resolution, the punch head tips were made with a roughly circular area, $30 \mu \mathrm{m}$ in diameter.

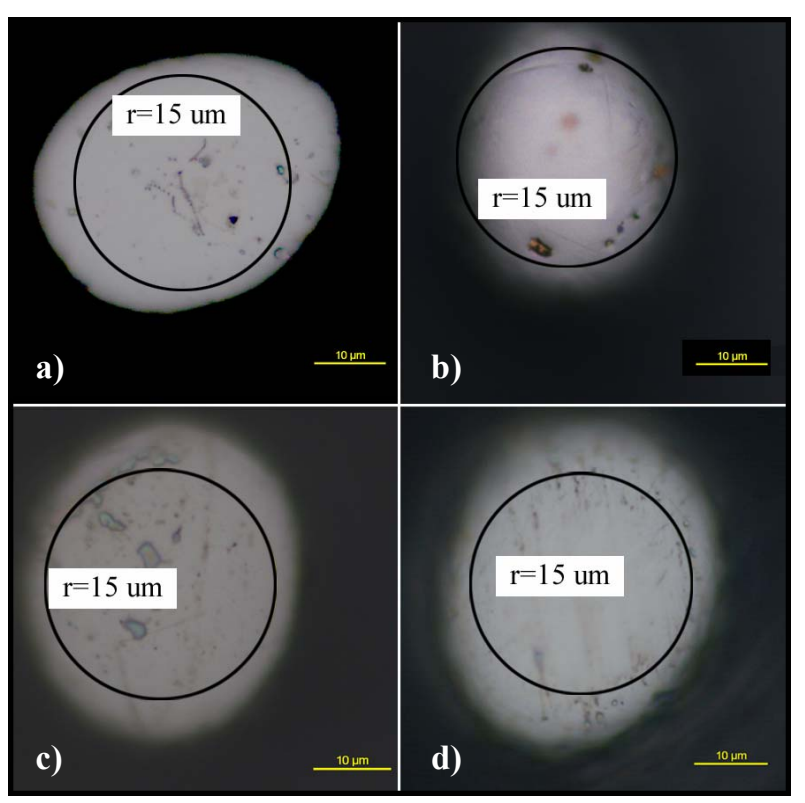

Fig. 6. Needle/punch shape and size

The base stage used in these experiments were glass microscope slides, whose size is $25 \times 75 \times 1.0$ $\mathrm{mm}$. In order to readily change between slides coated with different particles, a custom slide holder was made and used in this experiment. The microscope slides used were purchased pre-prepared with an extra positive electrostatic charge on the top surface. This resulted in strong adhesion of the particles onto the slide. In order to evenly spread the particles on the slide, three kinds of methods were tried. One was to spread the particles using pure water and then dry them at room temperature. Another was to blow the particles over the slide using an air duster at a distance of half a meter from the slide. The last method was to use a lens cleaning paper to spread 
the particles gently and an air duster to reduce the particle density. After some practice, each method worked perfectly, but the last method was used in the experiments.

\section{Experiment Design and Parameters}

The aim of this experiment was to measure the deformation properties of a single particle versus load force, the load rate effects on the deformation, and simultaneously the effects on the deformation due to differences in the experiment setup.

There were several initial user defined test parameters for the nano tester that affected the final experiment results, which were load rate, maximum force, and depth gate. Load rate is the amount the load force increases in each second, which remains constant during each particle deformation test. Depth Gate is a machine constant, and is the maximum distance that the machine can move the punch forward. The machine stops increasing load force when the load force reaches the maximum load force, even if the deformation does not exceed the depth gate. Vice versa, the machine stops increasing the load force when the deformation reaches the depth gate, even if the load force is still smaller than the set maximum force.

The sets of experiment were designed and carried out, mainly to explore the effect of the load rate. The deformation parameters used in these experiments are summarized in Table I, and selected according to the particle size and the machine resolution.

In total 23 experiments were conducted, as shown in Table I, where 8 tests were for the load rate at $0.5 \mathrm{mN} / \mathrm{s}, 11$ tests at $1 \mathrm{mN} / \mathrm{s}$, and 4 tests at $0.5 \mathrm{mN} / \mathrm{s}$. Also different initial load forces, maximum loads and depth gates were set up in the experiments.

In order to obtain the deformation of the punch when it indents directly on the glass, one experiment without particles was performed at a load rate of 0.5 $\mathrm{mN} / \mathrm{s}$, an initial load of $0.2 \mathrm{mN}$, a maximum load of $40 \mathrm{mN}$, and a depth gate of $4.783 \mu \mathrm{m}$.

\section{Results}

The results showed that the maximum force and depth gate had no clear effect on the experiment results if controlled within a reasonable range. Therefore, only the load rate effect is considered in this result section.
Table I: Experimental parameters

\begin{tabular}{|c|c|c|c|}
\hline Samples & $\begin{array}{c}\text { Load rate } \\
(\mathrm{mN} / \mathrm{s})\end{array}$ & $\begin{array}{l}\text { Maximum force } \\
(\mathrm{mN})\end{array}$ & $\begin{array}{l}\text { Depth Gate } \\
\qquad(\mu \mathrm{m})\end{array}$ \\
\hline T05-1 & 0.5 & 50 & 6.378 \\
\hline T05-2 & 0.5 & 50 & 6.378 \\
\hline T05-3 & 0.5 & 50 & 6.378 \\
\hline T05-4 & 0.5 & 50 & 6.378 \\
\hline T05-5 & 0.5 & 40 & 6.378 \\
\hline Т05-6 & 0.5 & 40 & 4.783 \\
\hline T05-7 & 0.5 & 40 & 4.783 \\
\hline T05-8 & 0.5 & 40 & 4.783 \\
\hline T10-1 & 1 & 40 & 4.783 \\
\hline $\mathrm{T} 10-2$ & 1 & 40 & 4.783 \\
\hline T10-3 & 1 & 40 & 4.783 \\
\hline T10-4 & 1 & 40 & 6.378 \\
\hline T10-5 & 1 & 40 & 6.378 \\
\hline T10-6 & 1 & 50 & 6.378 \\
\hline T10-7 & 1 & 50 & 6.378 \\
\hline T10-8 & 1 & 50 & 6.378 \\
\hline Т10-9 & 1 & 50 & 6.378 \\
\hline T10-10 & 1 & 50 & 6.378 \\
\hline T10-11 & 1 & 50 & 6.378 \\
\hline T20-1 & 2 & 50 & 6.378 \\
\hline T20-2 & 2 & 50 & 6.378 \\
\hline T20-3 & 2 & 50 & 6.378 \\
\hline T20-4 & 2 & 50 & 6.378 \\
\hline
\end{tabular}

\section{Indentation of the Punch on the Glass Slide}

As stated before, HSS or Ti punches and a glass sample stage were used in this experiment. Figure 7 compares the indentation of the punch on the glass slide with the deformation of a particle at $1 \mathrm{mN} / \mathrm{s}$. It shows that the indentation of the punch on the glass 
was much stiffer, and more linear than the deformation of the particle.

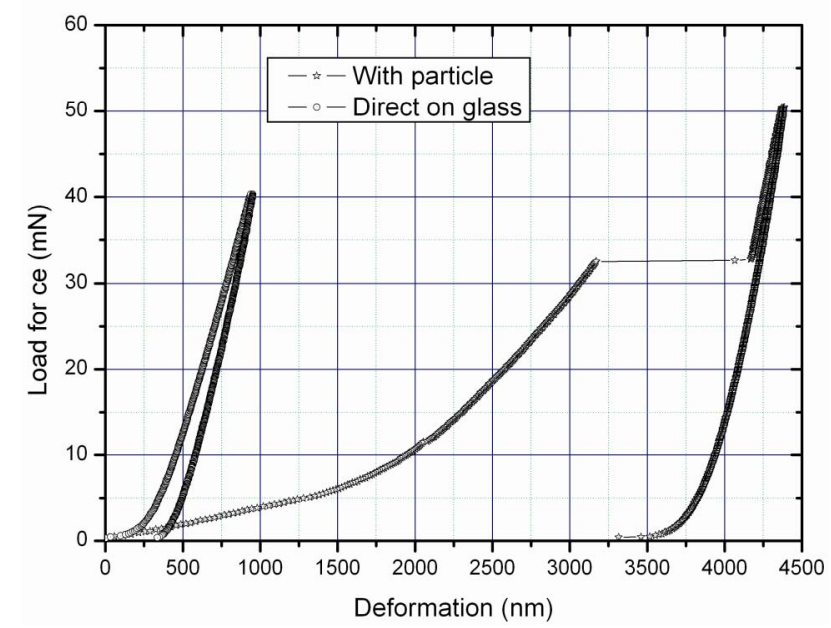

Fig. 7. Comparison of indentation of the punch directly on the glass slide with a particle

The deformation of the particle also showed much greater plastic deformation than the test directly on glass as shown in the figure, since the particle deformation was more than $3 \mu \mathrm{m}$ and the indentation on the glass was only $0.75 \mu \mathrm{m}$ when the load force was $30 \mathrm{mN}$. This demonstrated that the selection of the HSS punch and the microscope slide was suitable for deforming the ACA particles. The $T i$ punch was also tried in this experiment, and there was almost no difference between the HSS and $T i$ punch results so a HSS punch was used for all of the experiments presented in this paper.

\section{Deformation versus Load Force Profile}

From these sets of trials, the deformation versus load force was revealed as typically shown in Figure 7, which is for sample T10-10, where the load rate was $1 \mathrm{mN} / \mathrm{s}$, initial load $0.2 \mathrm{mN}$, maximum load 50 $m N$, and depth gate $6.378 \mu m$. The profile in the figure showed that the deformation increased gradually as the load force increased, but the stiffness (load force/deformation) was initially low i.e. for deformation up to $1.7 \mu \mathrm{m}$ and then increased for deformations greater than $1.7 \mu \mathrm{m}$. There was a sudden increase in deformation after the deformation reached $57 \%$ of the particle size, about $3.2 \mu \mathrm{m}$, at which the load force was $32 \mathrm{mN}$. Although the deformation increased by about $2 \mu \mathrm{m}$, there was almost no recorded change in the load force, resulting in the horizontal line seen in figure 7 . However, since the machine was operating in a load controlled mode, the load may have actually dropped during the crushing process, but this would have been hidden by the inertia of the pendulum.
The load then ramped up until the load force reached its set maximum, followed by the unloading process. It was found that the particles were crushed after this load and unload experiment, as shown in Figure 8 (a) and (b).

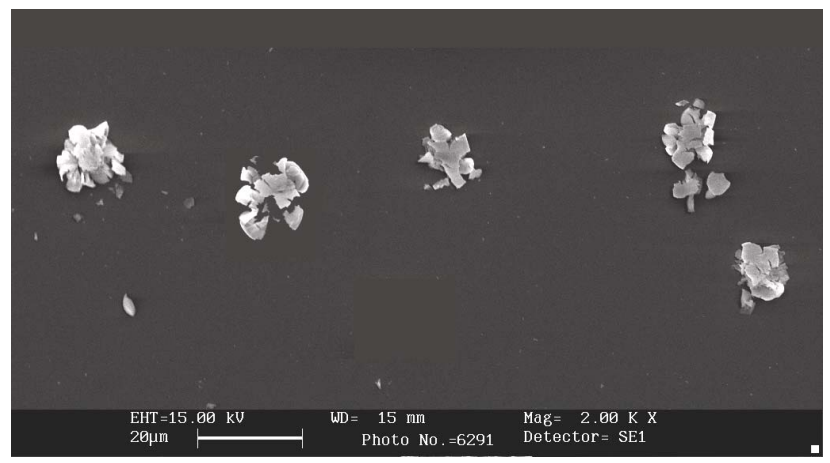

a) Crushed particles

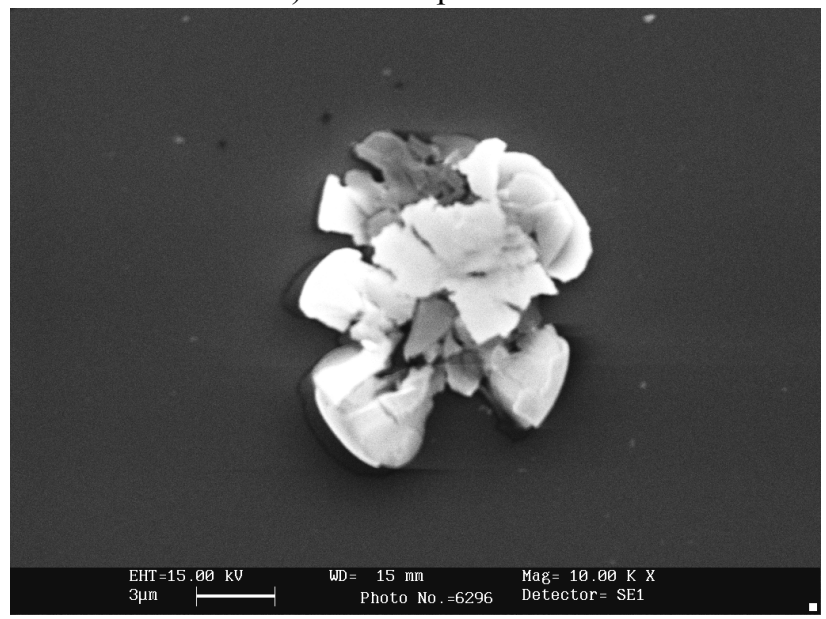

b) A single crushed particle

Fig. 8. Examples of crushed particles

\section{Experiment Results for Difference Load Rates}

The experimental results, for the different load rates as listed in Table I, are shown in Figures 9, 10 and 11. They show that the deformation behaviour for different load rates are different. For each load rate, the load curves vary significantly in terms of the load/displacement at which crushing occurs. The stiffness also varied for higher deformations, particularly at the slower load rates. Typical load and unload curves for the different load rate are shown in Figure 12. 


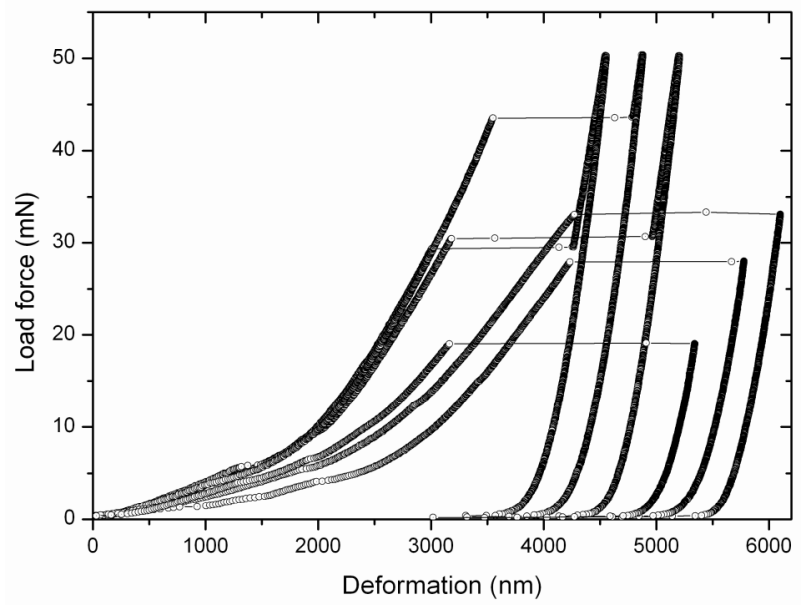

Fig. 9. Results for a load rate of $0.5 \mathrm{mN} / \mathrm{s}$

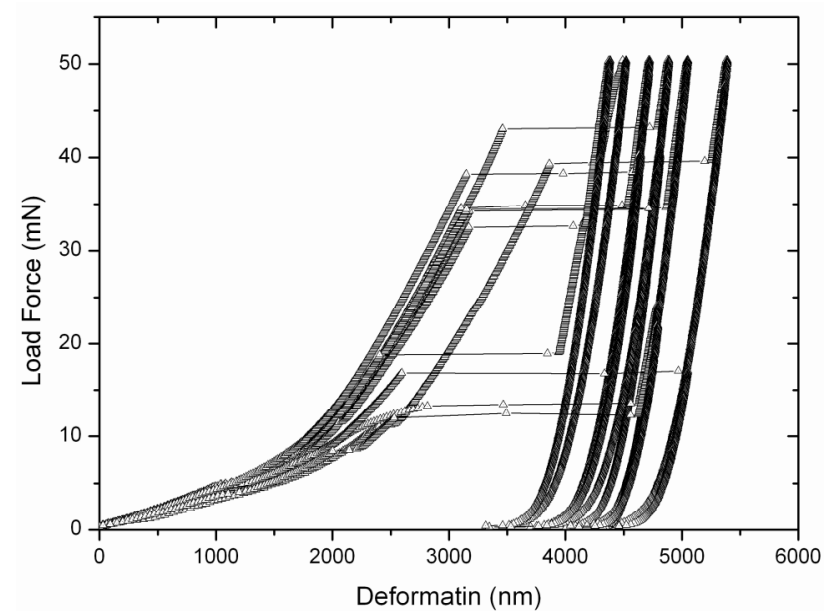

Fig. 10. Results for a load rate of $1 \mathrm{mN} / \mathrm{s}$

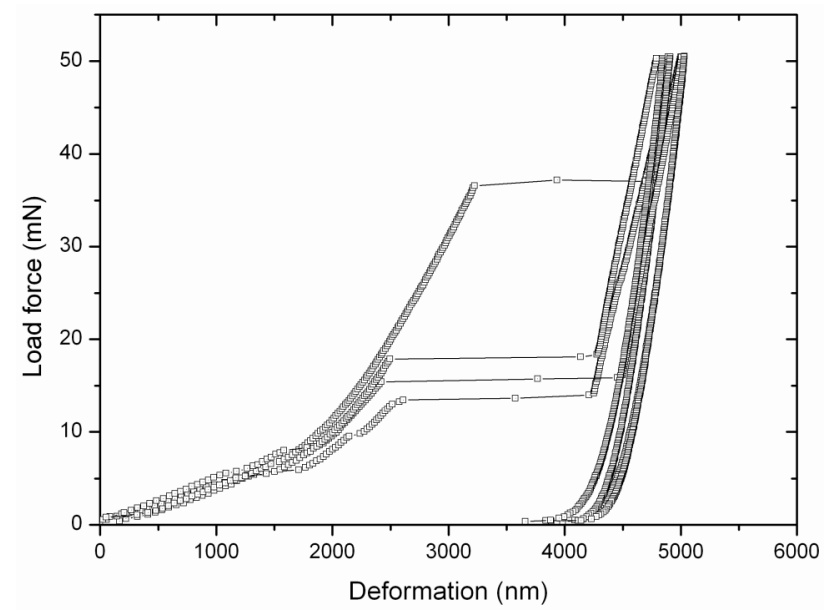

Fig. 11. Results for a load rate of $2 \mathrm{mN} / \mathrm{s}$

It is assumed that the left side of the horizontal lines in the load profiles indicate the start of particle crushing. This is referred to as the crush point in this work. Figure 12 compares the different loading rates where the results selected are for where the crush load force is near to the mean value for the respective load rate.

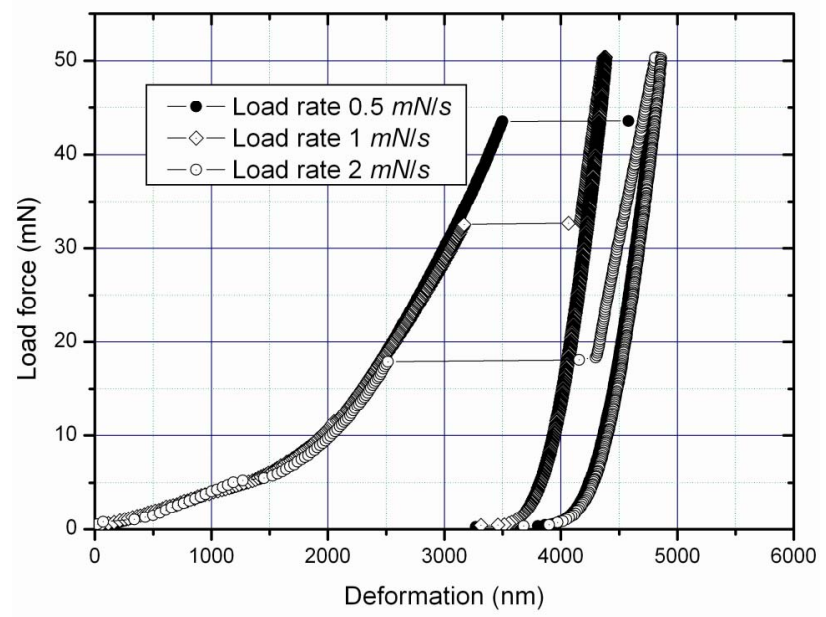

Fig. 12. Comparison between different loading rates

\section{Particle Crush Point}

The statistical analysis of the load rate effect on the particle crush point is shown in Figure 13. The results are for the mean value of the deformation, with the error bars indicating one standard deviation variation.

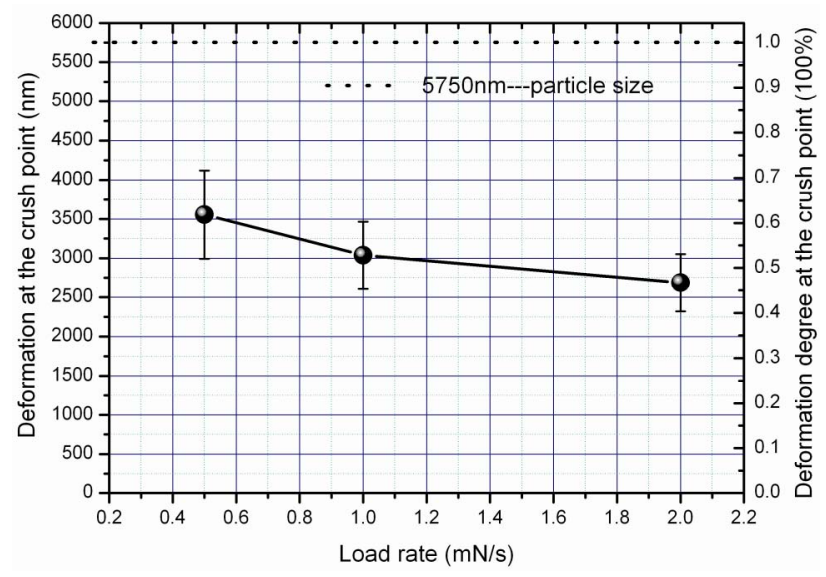

Fig. 13. Load rate effect on the particle crush point

The statistical analysis of the load rate effect on the particle crush force is shown in Figure 14. The results are the mean value of the load force at the crush point, also with one standard deviation shown. 


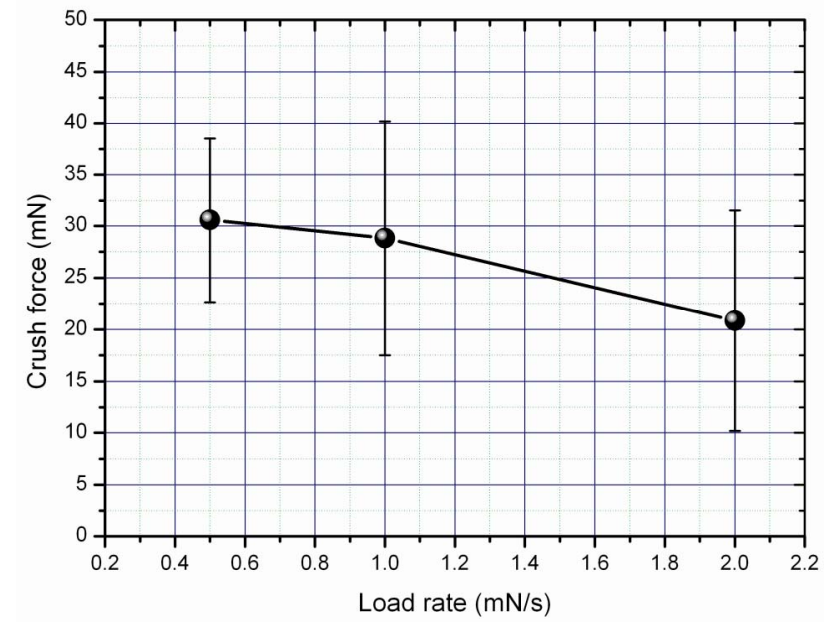

Fig. 14. Load rate effect on the particle crush force

\section{Discussion}

\section{The Complexities of the ACA Particle Deformation}

The results of the loading and unloading experiments for single ACA particles suggested that the effects of the test parameters on the particle deformations were complex. This complex behaviour was believed to be caused by the size of the particles, the sphere geometry of the particles, and the materials of the particles. Firstly, the particle size was small, and the surface roughness of the stage, the punch and the particles may have affected the deformation process. Secondly, the particles are not perfect spheres. Deformation of a ball is complex, since the strain is localized in very small areas of the particle when the compression starts, then the materials near the contact point locally deform plastically. Finally, the presence of the metal layers increased the complexity as well. In the deformation, the situation was firstly the stretching of metal layer, then the initiation and growing of cracks in metal layer, continually the initiation and growing of cracks in polymer, the crushing of the particle due to the large deformation. Simultaneously, plastic deformation occurs throughout the whole deformation process. Furthermore, the polymer material of the particle core had visco-elastic nature [1], where the local strain rate (depending on how fast the machine changes the deformation of the particle) was very important. These effect are a combination of geometrical non-linearity (large displacement and contact), and material non-linearity (plasticity, fracture and hardening/softening properties of the polymer core during deformation).

The deformation can be divided into 4 stages:
Stage I: The results, as shown in Figure 9, show that initially the deformation is approximately proportional to the load force applied until the deformation degree reached approximately $30 \%$. The particle stiffness was low in this stage because the initial deformation started from a point, and then the point increased into a circular area and grew larger and larger as the load force increased, but was still small compared to the particle diameter. It can be concluded that the deformation was mainly concentrated in the contact area in this step. Especially at the edges of the deforming particle [5].

Stage II: This stage started at about 30\% particle deformation, and continued until it reached about $55 \%$. The stiffness increased significantly during this stage, since the deformed contact area became larger compared to the particle in the stage I. Therefore, the shape of the deformed particle became more like a deformed cylinder, rather than a sphere, therefore it was much harder than in stage I.

Stage III: In this stage the deformation rapidly increased from about $55 \%$ to around $75 \%$. The very low stiffness during this stage of deformation suggested that the particle was crushing in this step.

Stage IV: In this stage, the particle had been crushed thoroughly, the particle became very hard and had almost no further plastic deformation. The process was that the punch continued to press the particle until it reached the maximum load, then the unload process started.

\section{Load Rate Effect on the Particle Crush Point}

Figures 13 and 14 show that the particle deformation and crush force were higher when the load rate was $0.5 \mathrm{mN} / \mathrm{s}$, at which the particles can be deformed by about $3500 \mathrm{~nm}$, or around $60 \%$ of the particle size. However, the crush point deformation dropped to about $52 \%$ of the particle size, about $3000 \mathrm{~nm}$, when the load rate was $1 \mathrm{mN} / \mathrm{s}$. And there was small drop in the deformation when the load rate was $2 \mathrm{mN} / \mathrm{s}$. The dropped deformation was around $2700 \mathrm{~nm}$, about $46 \%$ of the particle size. Therefore, it can be concluded that the load rate affected the particle deformation process, delaying the crushing significantly at lower load rates. This is considered to be due to the visco-elastic properties of the polymer particles. The error bars in the figure suggested that the lower the load rate, the more variable the crush point.

Figure 14 shows that the load force was high, about $31 \mathrm{mN}$, when the load rate was $0.5 \mathrm{mN} / \mathrm{s}$, but that it dropped a little, to less than $30 \mathrm{mN}$, when the load rate was $1 \mathrm{mN} / \mathrm{s}$. Therefore, there was no major 
difference in the crush load force between load rates of $0.5 \mathrm{mN} / \mathrm{s}$ and $1 \mathrm{mN} / \mathrm{s}$ if only the mean load force was considered. However, the crush load force was more variable at the higher load rate, since the error bar was bigger as shown in the figure. When the load rate was $2 \mathrm{mN} / \mathrm{s}$, the mean load force dropped to about $20 \mathrm{mN}$, which is more significant than the drop for the load rate of $1 \mathrm{mN} / \mathrm{s}$, and the error bar was similar to that for the load rate of $1 \mathrm{mN} / \mathrm{s}$. It is suggested that the high load rate $2 \mathrm{mN} / \mathrm{s}$ caused the particles to be more easily broken, as the deformation at crush point was only around $46 \%$ of the particle size, much smaller than the deformation in the load $0.5 \mathrm{mN} / \mathrm{s}$, however a little bit smaller than in the load $1 \mathrm{mN} / \mathrm{s}$, where the deformation was about $52 \%$ of the particle size. Moreover, the lower the load rate was, the higher the stiffness, and the larger the crush load force, as shown in Figure 12.

\section{Comparison with Previous Work}

The average mechanical properties of a number of ACA particles were previously measured by compressing many particles between flat plates [78]. The particles used in this research were smaller than theirs, e.g. the particles used by Kristiansen et al. were $10 \mu \mathrm{m}$ in diameter.

The particle deformation results from Kristiansen et al. and Shen were qualitatively similar to the results presented here, however the maximum load per particle was insufficient to reach the crush point i.e. only about $2.5-17 \mathrm{mN}$ per particle.

The effect of load rate on ACA particle deformation was also not studied in these previous works.

\section{Conclusions}

This paper has demonstrated a new technique for the mechanical deformation of a single ACA particle.

The results show that the load force affected the particle deformation, including the load and displacement at the crush point, and the variability of the deformation behaviour. They also show that at a low load rate, greater particle deformation before crushing can be obtained.

Future work will also measure the conductivity of a deforming ACA particle and the recovery (unloading) properties for uncrushed particles.

\section{Acknowledgments}

The authors would like to acknowledge Dr. Helge Kristiansen from Conpart AS, Norway [10], who provided the ACA particles used in the experiments and the SEM in figure 3.

\section{References}

1. Liu, J., Conductive Adhesive for Electronics Packaging. 1999, Electrochemical Publications Ltd, Port Erin, Isle of Man, British Isles:.

2. Liu, J., ACA bonding technology for low cost electronics packaging applications - Current status and remaining challenges. Soldering \& Surface Mount Technology, 2001. 13(3): p. 39-57.

3. Dou, G. B., Electrical Conductive Characteristics of ACA Bonding: A Review of the Literature, Current Challenges and Future Prospects. in Proceeding of the 6th IEEE Conference on High Density Microsystem Design and Packaging and Component Failure Analysis (HDP'04). 2004. Shanghai, China.

4. Holloway, M. Novel Anisotropically Conductive Film for Area Array Packaging. in Advances in Electronic Packaging. 1999: ASME.

5. Fu, Y., Wang, Y. L., Wang, X. T., Liu, J. H., Lai, Z. H., Chen, G. L., Willander, M., Experimental and theoretical characterization of electrical contact in anisotropically conductive adhesive. IEEE Transactions on Advanced Packaging, 2000. 23(1): p. 15-21.

6. Chiang, K.N., C.W., Chang, and J.D. Lin. Analysis of ACA/ACF package using equivalent spring method. in Proceedings of 3rd Electronics Packaging Technology Conference. 2000. Singapore.

7 Kristiansen H., Brudberg U., and Gulliksen M., Electrical and Mechanical Properties of Metal-coated Polymer Spheres for Anisotropic Conductive Adhesive. The Second IEEE International Symposium on Polymer Electronics Packaging. 1999. Gothenburg, Sweden.

8 Shen Y., Mechanical Properties of Conductive Particles for Anisotropic Conductive Adhesive (ACA). A Master Thesis of Material Science and Engineering, Chalmers University of Technology

$9 \mathrm{http}: / /$ www.micromaterials.co.uk

$10 \mathrm{http}: / / \mathrm{www} . c o n p a r t . n o$ 